European Journal for the Philosophy of Science 2019, 9:12

doi.org/10.1007/s13194-018-0236-2

'Water has a microstructural essence after all'

Carl Hoefer

ICREA and University of Barcelona

Department of Philosophy

Montalegre 6

08001 Barcelona, Spain

ORCID: 0000-0002-8020-4630

Genoveva Martí

ICREA and University of Barcelona

Department of Philosophy

Montalegre 6

08001 Barcelona, Spain

ORCID: 0000-0003-1269-4655

Contact: carl.hoefer@gmail.com

The research for this paper was funded by projects FFI-2016-76799-P and FFI-2015-70707-P of the Spanish MINECO. 


\title{
Water has a microstructural essence after all ${ }^{1}$ \\ Carl Hoefer \& Genoveva Martí \\ ICREA \& University of Barcelona
}

\begin{abstract}
In recent years attacks on the Kripke-Putnam approach to natural kinds and natural kind terms have proliferated. In a recent paper, (Häggqvist \& Wikforss, 2017) attack the once-dominant essentialist account of natural kinds. Häggqvist \& Wikforss also suggest that it is time to return to some sort of cluster-based descriptivist semantics for natural kind terms, thus targeting both the metaphysical and semantic tenets that underpin the Kripke-Putnam approach. In our paper we want to challenge both parts of Häggqvist and Wikforss' project. We will argue that the anti-essentialist considerations and arguments they raise against the Kripke-Putnam view are far from compelling in some cases, and certainly not decisive against a reasonable form of the view. On the semantic side, although Häggqvist and Wikforss give few details about what a viable cluster-based descriptivist theory should look like, we will argue that one can already see the approach to be a non-starter. Ignorance and error arguments of the kinds provided by Kripke and Putnam continue to be decisive objections. The only way we can see to save the cluster descriptivist approach is to make the essential properties postulated by Kripke and Putnam become essential features of the descriptive cluster. But this makes the success of the approach parasitic on the correctness of the Kripke-Putnam view.
\end{abstract}

\section{Introduction}

What determines the extension of a natural kind term? The dominant answer to this question has been one that rejects descriptivism. ${ }^{2}$ A bit of stuff counts as 'iron' not because it satisfies some stereotypical description, but rather because it bears the same-substance relation to the samples that were originally singled out by humans as a kind and dubbed 'iron'. According to Kripke and Putnam (hereafter: K\&P), being the same substance is a matter of having the same underlying essential nature, usually something to do with

\footnotetext{
${ }^{1}$ Acknowledgments: We wish to thank Helen Beebee, Alexander Bird, Catherine Elgin, Robin Hendry, and an anonymous reviewer for very helpful comments on the first version of this paper.

${ }^{2}$ Here we mean classical descriptivism. Our discussion does not extend to causal descriptivism, a view that incorporates part of the mode of determination of the extension postulated by Kripke and Putnam into the reference-fixing description.
} 
microstructure; what this means in any particular case is something science typically tries to, and often does, reveal to us. But the meaning of the kind term, and hence its extension, is already fixed before science reveals any details (when it does) about that underlying essential nature.

Over the years a number of philosophers have attacked the K\&P picture of the metaphysics of natural kinds and the corresponding semantic story by trying to show that it is naïvely oversimplified and in conflict with real science. Here we will focus on a recent paper by Häggqvist and Wikforss (hereafter: $\mathrm{H} \& \mathrm{~W}$ ) as one of the latest examples of this current (Häggqvist \& Wikforss, 2017), but the thrust of their arguments is shared by others. ${ }^{3}$ We will argue that the metaphysical picture offered by $\mathrm{K} \& \mathrm{P}$ is not as vulnerable as $\mathrm{H} \& \mathrm{~W}$ contend, at least when it comes to non-living substance kinds such as water and gold. We will not address biological taxa, in part because we believe that a simple genetic-essence story fails for such natural kinds.

The K\&P view presupposes that a kind such as water has some microstructure that is unique to it and which partly causes or explains the familiar stereotypical properties of water which have been accessible to humans all along (e.g., being transparent, odorless, nonpoisonous, etc.). The thrust of the objection to the K\&P story, for the case of water, involves (i) noting that water has many different microstructures, with the presence of $\mathrm{H}_{2} \mathrm{O}$ molecules being just part of the story, and (ii) claiming that equating water with $\mathrm{H}_{2} \mathrm{O}$ is neither true nor an ascription of a microstructure.

Against $\mathrm{H} \& \mathrm{~W}$, we will argue that the observations of philosophers of chemistry concerning the complexity of water's micro-level features do not show, by any means, that water does not have essential properties, ones correctly describable as "microstructural". So, the K\&P view, for many chemical substances at least, does not crumble after all. ${ }^{4}$ Nor can the semantic part of their view be replaced by a more-sophisticated version of cluster descriptivism, as H\&W suggest, because the standard sorts of ignorance and error arguments

\footnotetext{
${ }^{3}$ See, for example, (Beebee \& Sabbarton-Leary, 2010), (Needham, 2011), or (Leslie, 2013).

${ }^{4} \mathrm{We}$ will restrict our discussion to the case of water, as it has been the chemical substancekind about which the strongest challenges to K\&P have been mounted. Gold and most other stable elements and compounds will surely be tractable if water can be brought back into line. Interesting questions may arise, however, about certain elements and compounds whose instantiations are extremely unstable and short-lived. For example, (Beebee \& SabbartonLeary, 2010) discuss the highest elements in the periodic table and how their names may fail to fit the mold of K\&P semantics. For reasons of space we will not address such kinds, but we do not feel they constitute a serious challenge to the K\&P view, since the latter does not require that its semantic and metaphysical theses be applicable to every element of the periodic table or molecular compound.
} 
that led philosophers of language to abandon descriptivism in the 1970s still work against such a view. The only way, we will argue, for a cluster descriptivist semantics of the kind $\mathrm{H} \& \mathrm{~W}$ propose to evade those arguments is to build precisely the properties that $\mathrm{K} \& \mathrm{P}$ consider essential into the cluster, as essential members of the cluster. But then the semantic defensibility of the account turns out to be parasitic on the correctness of the K\&P view.

\section{The Kripke-Putnam view}

It is important not to lose sight of the kind of semantic theory that K\&P were arguing against. K\&P were both reacting against classical descriptivism, a view according to which the reference, or extension, of any term is determined by a definite description cognitively accessible to the competent speakers that use the term. Or as Putnam put it, that meaning (understood as that which determines reference) is in the minds of users. The only way reference can be established, according to the descriptivist, is via such a definite description.

Kripke's arguments in Naming and Necessity strived to show that this is not so, that reference can be achieved without the mediation of some definite description that speakers have in mind when they use a term. For one thing, speakers do not always have a definite description in mind: people who use 'Feynman' refer to Feynman, Kripke tells us, even if all they associate to the name 'Feynman' is 'famous physicist', descriptive information that is insufficient to distinguish Feynman from Gell-Mann and hence fails to determine a unique referent. For another thing, no matter which description speakers have in mind, the individual selected by that description may not be the referent: people who use 'Columbus' are not referring to a Viking in the 11th century even if all they associate to 'Columbus' is the description 'the first European to set foot in America'. ${ }^{5}$

Of course, Kripke's arguments do not entail that speakers cannot use an expression descriptively, for instance that speakers cannot decide to consistently use a proper name to refer to whoever satisfies some definite description. What Kripke's arguments do is open the door to the possibility that speakers use expressions to refer without having a specific description in mind whose role is to select the referent.

Putnam, focusing on kind terms, also targets the descriptivist notion that "meaning is in the head." Typically, according to Putnam, when speakers introduce a natural kind term

\footnotetext{
${ }^{5}$ These are the arguments from ignorance and error, also known as semantic arguments, against descriptivism offered by Kripke. Kripke presented also other powerful, modal and epistemic, arguments against descriptivism.
} 
they have the intention of applying the term to samples or objects that are the same kind of thing as some ostended paradigms. What makes an object or a sample an exemplar of the same kind as the paradigms may well be, according to Putnam, beyond the grasp of the speakers that introduce and successfully use the term. ${ }^{6}$

Thus for instance 'water' applies to some sample of stuff just in case the sample in question bears a certain relation to the original samples. In the case of water, Putnam postulates, that is the relation of being the same substance as. The role of Putnam's Twin Earth case is to show that what being the same substance as consists in does not have to be in the minds of speakers. In the case of water, that relation does not consist in a definite description that captures the well known superficial properties that speakers usually attribute to water: water and Twin Earth "water" are posited to share all their superficial properties. Yet, Twin Earth water has a microstructure that differs from the microstructure of water and so, Putnam contends, it is not the same substance as water.

In the Twin Earth case microstructure emerges as the condition that determines the correct application of the term 'water'. But the moral of the Twin Earth case can be applied to other scenarios where microstructure or other underlying properties are not at stake. Imagine that a group of explorers found the remnants of an old culture. Among their findings were a series of objects, superficially rather similar, clearly made by intelligent beings, objects that the explorers did not hesitate to classify as some sort of tool and for which they introduced a term N. The explorers might have been quite sure that the objects in question had some very specific function even if they could not fathom what that function was. Years down the road, thanks to the discovery of other types of remnants, experts manage to discover the function of those objects, and this allows scholars to extend the application of $\mathrm{N}$ to other objects that were not so superficially similar to the original paradigms, and also to exclude some very similar objects that were shown to have been just decorative, devoid of any other function. The scholars that used $\mathrm{N}$ with the intention of referring to objects that had some specific function they could not quite pinpoint surely did not have in mind a description capturing the correct condition of application of N. Yet they were referring to a well delimited class of objects. Very much like in Putnam's original Twin Earth case, successful reference can be achieved in the absence of a reference-determining definite description.

$\mathrm{K} \& \mathrm{P}$ are arguing against a hegemonic conception of reference determination, one according to which reference has to be mediated by a definite description in the mind of the

${ }^{6}$ For an in depth analysis of how these terms are typically introduced and an exploration of the metaphysical and epistemic consequences, see (Nimtz, 2017). 
speaker. Their arguments open the door to the possibility that reference is achieved without such mediation. K\&P's approach does not entail that reference can never be determined via a definite description. ${ }^{7}$

It is important to keep in mind that, from a purely semantic point of view, the moral of the Twin Earth case originally proposed by Putnam has to do with the cognitive access to the conditions that determine the reference of a term. But the Twin Earth case goes beyond the purely semantic point and has also a metaphysical lesson, for it is meant to prompt us to conclude that, in the case of water, what makes a sample of stuff water, and hence what determines the correct application of 'water' to it, depends on its having a certain microstructure. Mutatis mutandis, Putnam's conclusion as regards water and 'water' should extend also to most other natural kinds and natural kind terms.

Häggqvist and Wikforss' purpose is to criticise what they call 'the KP-thesis': "the thesis that extensions of natural kind terms are determined, in the actual and possible worlds, by underlying, essential features of samples in the speaker's environment' (p. 2). The thesis, like the moral of the Twin Earth case, has a semantic and a metaphysical component, for part of it focuses on the determination of the extension of natural kind terms; but a crucial part has to do with what makes samples of stuff be the kind of substance they are. In the case that Häggqvist and Wikforss discuss at length, the first issue of contention is whether what makes a sample of stuff be water is its microstructure, specifically, being composed of molecules of $\mathrm{H}_{2} \mathrm{O}$. So let us focus on that issue first. ${ }^{8}$

\section{The problems of 'Water is $\mathrm{H}_{2} \mathrm{O}$ '}

Although we all learn in grade school that water is $\mathrm{H}_{2} \mathrm{O}$, it turns out that this is not a precisely accurate statement (even if we restrict ourselves to water that is free of all

\footnotetext{
${ }^{7}$ This is why raising doubts about the applicability of the approach to, say, biological kind terms or terms for unstable elements does not constitute, in and of itself, a challenge to the $\mathrm{K} \& \mathrm{P}$ story about kinds such as iron and water, nor a defense of descriptivism.

${ }^{8}$ According to $\mathrm{H} \& \mathrm{~W}$ the appeal to microstructure is part of an attempted solution to the qua problem (H\&W: 5-6). The bulk of H\&W's paper does not focus on the discussion of the details of the qua problem, and thus we do not make it a central feature of our argument. Nevertheless we wish to note that we are sceptical about some of the assumptions that generate the qua problem and about its attempted solutions; but a full discussion of this issue is beyond the scope of this paper.
} 
contaminants containing other types of atoms besides hydrogen and oxygen). A sample of water, no matter how pure, is not a pile of $\mathrm{H}_{2} \mathrm{O}$ molecules. ${ }^{9}$ A more complete and correct description of what water is like at the micro-level is taken, by a number of philosophers of science, to pose two sorts of problems for the K\&P view. First, they claim that to say that the microstructural essence of water is being- $\mathrm{H}_{2} \mathrm{O}$ is problematic because in chemistry, ' $\mathrm{H}_{2} \mathrm{O}$ ' stands for a composition ("composed of oxygen and hydrogen atoms bonded in a 1:2 ratio") rather than a microstructure. Second, what $20^{\text {th }}$ century chemistry revealed in ever-increasing detail is that there is no such thing as the microstructure of water. The micro-level details vary significantly depending on temperature, pressure, presence of contaminants, and other things, as we will see shortly. Therefore water has no microstructural essence, contrary to what the K\&P view presupposes. Let's look at the apparent problems in a bit more depth.

First, H\&W object: "To many, Kripke and Putnam appeared to be offering a specific structure as relevant. But ' $\mathrm{H}_{2} \mathrm{O}$ ' is not a description of micro-structure; it describes chemical composition, which here means just molar proportions. Structural isomerism entails that different substances may share a single composition. A simple inorganic instance is $\mathrm{C}_{3} \mathrm{H}_{8} \mathrm{O}$, which may be propanol, isopropanol, or methoxyethane... . Composition just won't cut it." (p. 7) But this objection can be swiftly set aside. First, as H\&W themselves note shortly after this passage, water has no structural isomers, so ' $\mathrm{H}_{2} \mathrm{O}$ ' is not ambiguous in the way that ' $\mathrm{C}_{3} \mathrm{H}_{8} \mathrm{O}$ ' is. $\mathrm{H} \& \mathrm{~W}$ appear to be assuming that $\mathrm{K} \& \mathrm{P}$ are implicitly endorsing the identification of microstructural essence with chemical composition; but we see no reason to attribute this implausibly naïve position to either philosopher. It would be more reasonable to suppose that, when it comes to compounds with more than one structural isomer, K\&P would incorporate the structural features that distinguish the isomers in their account of the relevant, essential microstructure for such natural kinds. $\mathrm{H} \& \mathrm{~W}$ do mention that $\mathrm{K} \& \mathrm{P}$ have this way out of this first problem, and then go on to present the multiple further problems that they see for the 'Water is $\mathrm{H}_{2} \mathrm{O}$ ' thesis.

We will look at those further problems in the rest of this section, and respond in the next. But we wish to point out a problem with H\&W's first remark in the quote above, that being $\mathrm{H}_{2} \mathrm{O}$ is not a microstructural description. Given their appeal to the $\mathrm{C}_{3} \mathrm{H}_{8} \mathrm{O}$ example, they appear to have in mind here a notion of 'structural' that requires specification of

\footnotetext{
${ }^{9}$ However, it's not far from being one: the proportion of all dissociative products (ions) and non-standard water molecules (e.g. $\mathrm{D}_{2} \mathrm{O}$, where $\mathrm{D}$ stands for the deuterium isotope of hydrogen) taken together is less than $0.03 \%$.
} 
spatial/geometric properties or relations, or perhaps of the bonding relations between atoms, which ' $\mathrm{H}_{2} \mathrm{O}$ ' does not do but ' $\mathrm{H}-\mathrm{O}-\mathrm{H}$ ' does, or even better:

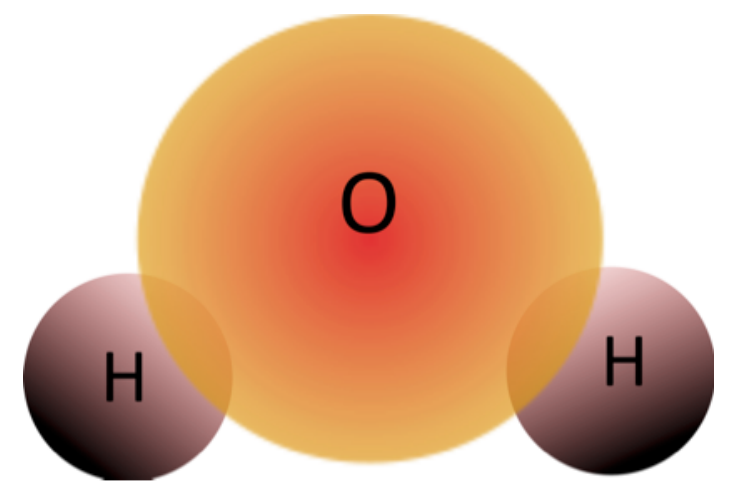

Fig. 1: representation of $\mathrm{H}_{2} \mathrm{O}$ molecule.

But structure need not involve spatial, geometric, or even bonding relations. Being composed of two hydrogen and one oxygen atoms is surely a structural property that a molecule may possess. And such compositional structure is plausibly essential for at least many chemical natural substance kinds (in the sense of being necessary, not sufficient!). Nothing can be isopropanol without having molecular composition-structure $\mathrm{C}_{3} \mathrm{H}_{8} \mathrm{O}$, although having this composition-structure is not sufficient to make a molecule be an isopropanol molecule, as $\mathrm{H} \& \mathrm{~W}$ rightly note. ${ }^{10}$

Let's turn back to the case of water. H\&W argue that there are many further reasons why one cannot consider that 'Water is $\mathrm{H}_{2} \mathrm{O}$ ' captures a microstructural essence of water in the way that K\&P supposed. The most important reasons appear to be (i) facts that show that water has many different specific, complicated structures at different pressures and temperatures; (ii) the fact that only in certain very specific circumstances (water vapor in certain conditions) is water composed of unlinked individual $\mathrm{H}_{2} \mathrm{O}$ molecules; and (iii) the fact that even molecular $\mathrm{H}_{2} \mathrm{O}$ comes in two distinct "flavors", orthowater and parawater. We will look at these in turn in the rest of this section, and give our responses in the next.

${ }^{10}$ Or rather, nothing can be isopropanol without being predominantly composed of molecules with composition-structure $\mathrm{C}_{3} \mathrm{H}_{8} \mathrm{O}$. The discussion of the complexity of water's composition and structure below will clarify the need for this sort of qualification. 
As regards (i), $\mathrm{H} \& \mathrm{~W}$ write: "Liquid water at any moment consists partly of $\mathrm{H}+$ and $\mathrm{OH}-$ ions, into which $\mathrm{H}-\mathrm{O}-\mathrm{H}$ molecules constantly dissociate, as well as of rapidly lengthening and shortening polymers of $\mathrm{H}-\mathrm{O}-\mathrm{H}$ molecules, ions, and combinations of these. Polymerization and ionization rates vary with temperature and pressure; hence, on any reasonable notion of 'structure' at the molecular lever, the structure of liquid water varies with temperature and pressure. Surely it is best, if one wants to think of structure at this level, to avoid the singular definite altogether and grant that water has lots of different structures, many of them immensely complex." (p. 7). This is of course scientifically correct, and importantly so; many of the most familiar and useful properties of liquid water, for example, depend crucially on the presence of the ionic dissociative components (mostly $\mathrm{H}_{3} \mathrm{O}^{+}$and $\mathrm{OH}^{-}$, rather than $\mathrm{H}^{+}$and $\mathrm{OH}^{-}$, in fact) - even though the concentration of these ions compared to molecules of $\mathrm{H}_{2} \mathrm{O}$ is of the order of $10^{-7}$. But there is more complexity than just this. Water also always has small, trace amounts of $\mathrm{D}_{2} \mathrm{O}$ and $\mathrm{T}_{2} \mathrm{O}$ as well (where ' $\mathrm{D}$ ' stands for deuterium, the unstable isotope of hydrogen with one neutron attached, and ' $\mathrm{T}$ ' for tritium, which has two neutrons). $\mathrm{D}_{2} \mathrm{O}$ and $\mathrm{T}_{2} \mathrm{O}$ should perhaps be counted as different substances, since (relatively) pure macroscopic samples of them differ markedly from water in observable, stereotypical properties. For example, $\mathrm{D}_{2} \mathrm{O}$ will kill you if you try to substitute it for the water in your daily diet for an extended period. But, stubbornly, they are always there in samples of water: so they are part of the true microstructure of canonical samples of water (those used in baptizing the kind), but are (arguably) not " $\mathrm{H}_{2} \mathrm{O}$ ". ${ }^{11}$

Point (ii) is not about things that might be thought to be "impurities" but which are stubbornly hard to eliminate and in fact always present, but rather about the way that the $\mathrm{H}_{2} \mathrm{O}$ molecules that are present (and that vastly outnumber the rogue elements) link together into groups or chains via hydrogen bonding. (Needham, 2002) writes: "A number of models have been proposed to describe the intermolecular structure of liquid water. ... [One] model views the liquid as comprising a mixture of single molecules together with clusters of hydrogenbonded polymers in which one molecule is linked with four others. The clusters continually break and reform, giving every water molecule the same average environment over sufficiently long periods of time." (p. 222). This, too, is surely microstructure; but the

${ }^{11}$ Similar remarks apply to isotopic variants where the oxygen atom has more neutrons, e.g. $\mathrm{H}_{2}{ }^{17} \mathrm{O}$. We say "arguably not $\mathrm{H}_{2} \mathrm{O}$ " because it depends on whether one considers deuterium and tritium atoms to be hydrogen atoms (this being in accord with the standard practice of individuating elements by number of protons in the nucleus), and whether one takes the ' $\mathrm{H}$ ' in ' $\mathrm{H}_{2} \mathrm{O}$ ' to stand only for ordinary hydrogen, or instead to represent ordinary hydrogen and its isotopes. 
varieties and permutations that water (and ice and vapor) samples instantiate are innumerable. So point (ii) further supports H\&W's conclusion that "[It is best to] grant that water has lots of different structures, many of them immensely complex." (p. 7)

Finally, point (iii), even $\mathrm{H}_{2} \mathrm{O}$ molecules themselves come in two subspecies which are hard - but not impossible - to separate in the lab: orthowater and parawater. The difference lies in the spins of the protons making up the molecule: if they are aligned, it is an orthowater molecule, and if they are opposed, it is a parawater molecule. These subspecies presumably behave differently in magnetic fields, and perhaps in other ways as well. H\&W point out that by one commonly used test for distinctness of chemical substances, the entropy of mixing test, orthowater and parawater count as distinct substances. By another criterion, the Gibbs phase rule, however, all samples of water come out as "the same substance". So what can, or should, the proponent of the K\&P view say about the fact that water is a mixture of orthowater and parawater molecules - and about points (i) and (ii) just described? We will now argue that these apparent problems can be solved in one stroke.

\section{Complexity and stability of structure}

A response to all these challenges on behalf of the $\mathrm{K} \& \mathrm{P}$ view should begin with a dose of charity. In Is Water $\mathrm{H}_{2} \mathrm{O}$ ?, Hasok Chang (Chang, 2012) cites Putnam as having said that "The extension of 'water' ... is the set of all wholes consisting of $\mathrm{H}_{2} \mathrm{O}$ molecules", and $\mathrm{H} \& \mathrm{~W}$ follow Chang here. But what Putnam (1975) actually wrote was: "The extension of 'water' ... is the set of all wholes consisting of $\mathrm{H}_{2} \mathrm{O}$ molecules, or something like that." (p. 141, emphasis ours). We think that Putnam knew that more could be said, and was deliberately oversimplifying. This is confirmed by his later (Putnam, 1990) discussion of the case of water where, after indicating that he is assuming high school chemistry (where one learns that water is $\mathrm{H}_{2} \mathrm{O}$ ), in footnote 3 Putnam notes: "I shall stick to high school chemistry because the actual quantum-mechanical picture of the structure of water is immensely complicated." (p. 57). So Putnam was aware that, in full detail, the detailed microstructure of ordinary water is much more complicated than being a pile of $\mathrm{H}_{2} \mathrm{O}$ molecules, and did not think that this undercut the [limited] microstructural essentialism that he defended. Nor do we.

All this complexity might seem to make it hopeless to try to defend that there is such a thing as the microstructural essence of water, much less that that essence is being $\mathrm{H}_{2} \mathrm{O}$. But a key fact about water and many other naturally-occurring chemical compound kinds, one not discussed by $\mathrm{H} \& \mathrm{~W}$, is that under a given set of specified conditions, water will always settle 
down into having a certain specific micro-level structure and composition. This tendency to equilibrate into a predictable structure, with predictable properties and behaviors, is part of what makes it justified to consider water a natural kind. For example, if one starts with a bucket of pure parawater, and sets it aside for a few hours, next time you look it will be a bucket of ordinary water, with the usual ratio of parawater to orthowater. Moreover, if God somehow created a bucket containing nothing but a pile of perfect, unbonded $\mathrm{H}_{2} \mathrm{O}$ molecules (para-, ortho-, or any mixture thereof) and handed it to you, it too, after a while, would turn into an ordinary sample of (unusually pure) water: full of dissociative ionic products, isotopic variants, and ever-shifting polymeric bonded configurations. ${ }^{12}$ The natural, equilibrium microstructure of water at given temperature and pressure conditions may be complicated to specify, but it exists and can be specified. And because it is stable and reliable, we can now see a clear sense in which $\mathrm{K} \& \mathrm{P}$ were right on target: water is essentially composed of $\mathrm{H}_{2} \mathrm{O}$ molecules, in the stable structural configurations into which such samples evolve with physical necessity for given conditions. ${ }^{13}$

But equally, we can see that the detailed structural configurations, which vary with temperature, pressure and the presence of trace impurities, are properly seen as being merely the fine-print details. What is most important about water's microstructure, and is the explanatory starting-point for understanding the detailed structures we have surveyed above, is simply that water is a substance composed predominantly of $\mathrm{H}_{2} \mathrm{O}$ molecules. Much further structural detail follows from this basic structural fact, but the basic structural fact is rightly regarded as essential to being water.

We believe that these observations take care of all the apparent problems $\mathrm{H} \& \mathrm{~W}$ raise for the $\mathrm{K} \& \mathrm{P}$ claim that the microstructural essence of water is to be $\mathrm{H}_{2} \mathrm{O}$. Rather than saying that water is necessarily made up of $\mathrm{H}_{2} \mathrm{O}$ molecules, Kripke or Putnam might have instead written:

"Samples of water necessarily consist predominantly of $\mathrm{H}_{2} \mathrm{O}$ (both orthowater and parawater) molecules, in various polymeric configurations, plus their dissociative products $\mathrm{H}^{+}, \mathrm{H}_{3} \mathrm{O}^{+}$and $\mathrm{OH}^{-}$, with minor amounts of isotopic compounds such as

\footnotetext{
${ }^{12}$ Since the settling-down phase would involve considerable amounts of chemical reaction, we suppose that you should handle this bucket of water with care; but we are not sure how much heat would be given off in the settling-down phase, nor how quickly!

13 (Hendry, 2006), who also defends the existence of a microstructural essence for water against the attacks of Needham and others, puts it like this: "My proposal, then, is that water is the substance formed by bringing together $\mathrm{H}_{2} \mathrm{O}$ molecules and allowing them to interact spontaneously." (p. 872)
} 
$\mathrm{H}_{2}{ }^{17} \mathrm{O}, \mathrm{D}_{2}{ }^{16} \mathrm{O}$ (etc.), with the relative concentrations of these components stabilizing into characteristic ranges which depend on temperature, pressure, and the impurities and/or electromagnetic fields present."

We find it understandable that they chose not to go into such detail in presenting their semantic and metaphysical claims. ${ }^{14}$

A crucial part of the K\&P view that $H \& W$ mostly set aside is the fact that the microstructure of water and other chemical natural kinds explains why the substance has its characteristic or stereotypical properties, the properties that prompt humans to single out and name these kinds in the first place. For gold, the stereotypical properties included its lustrousness and dark-yellowish color, high density, malleability, etc. For water, they included properties like being odorless, transparent, thirst-quenching, necessary for life, good for dissolving many solid substances, and so forth.

In fact, $H \& W$ come close to denying that real science actually satisfies the explanatory role that the K\&P thesis postulated. Following (Leslie, 2013), H\&W hypothesize that ... the intuitive support for the Kripke/Putnam semantics results from a stubborn cognitive bias towards expecting essences where none exists: 'The intuition that such essences must exist is no more than an expression of a belief set that is firmly in place by the middle of the preschool years, but this belief set does not comport with the complexities of actual science'. (p. 17)

We see things differently. The intuition that such essences exist is a deeply rooted realist presupposition, equivalent to the assumption that an explanation exists for the stable, reliable properties of the many apparently-stable, naturally occurring kinds that we have identified; and that we have already in fact discovered many such explanations. This is not pre-school metaphysics, it's just scientific realism. That the "essences" science has delivered to us are

\footnotetext{
${ }^{14}$ The use of the word 'necessarily' in this specification of the essential microstructure of water would seem to cover all possible worlds. As Putnam noted in (1990), if one considers all metaphysically possible worlds, including ones in which the laws of nature (if any!) are different - perhaps minutely different, perhaps greatly different - it can be difficult to hold on to any clear intuitions concerning, e.g., whether a certain molecular substance even counts as a sample of (predominantly) $\mathrm{H}_{2} \mathrm{O}$ molecules. To avoid a complicated discussion that is not necessary for our purposes in this paper, we suggest the reader interpret the modal claim as restricted to possible worlds that have the same physical laws as our universe (which is what Putnam did in (1990)). This restriction does not affect the semantic issues to which we will turn in sections 5 and 6. (It is worth noting, in passing, that almost all of the counterfactual scenarios used by Kripke and Putnam in establishing their semantical claims can be understood as set in worlds with the same laws as those of our universe).
} 
complicated in many cases is true but is beside the point; they are there nonetheless. To put it another way, it's just not true that nature is full of cases where lots of radically different micro-structures give rise to one and the same set of macro-level observable characteristics. ${ }^{15}$ This may happen in a few rare cases - we do not want to rule it out a priori - but the opposite is the rule: microstructure determines and (together with the laws of physics and chemistry) explains macroscopically observable properties, and does so uniquely. To support this claim, let's reconsider Putnam's Twin Earth story in light of all the above.

\section{On some other reasons for anti-essentialism. Twin Earth revisited.}

Of course, it might be argued that it is one thing to accept that water does have a microstructure and that the microstructure plays an important explanatory role. A different thing is to accept the stronger claim that the microstructure of water constitutes the essence of water, that it is what makes water the substance it is or, in short, to accept the metaphysical moral of Putnam's Twin Earth story. We have argued that the argument deployed by

Häggqvist and Wikforss among others does not constitute a threat to the essentialist stance Putnam defends. But there may be other ways of casting doubt on the metaphysical import of the Twin Earth case.

In order to examine that threat and its import we need to focus with a bit more detail on the structure of the Twin Earth scenario. In his original presentation Putnam envisages a group of explorers that arrive in a planet where there is a liquid that "is indistinguishable from water at normal temperatures and pressures" (p. 223). Other characteristics that Putnam mentions include quenching thirst and filling lakes and oceans on Twin Earth. Now, those are properties of the liquid in question that the explorers observe at first sight; upon discovering that the chemical formula of that liquid is not $\mathrm{H}_{2} \mathrm{O}$ (plus dissociative byproducts, isotopic variants etc., in the stable ratios that water settles into in equilibrium, as specified in section 4) but some other complex formula that can be abbreviated as XYZ, the explorers, Putnam contends, would conclude that despite the superficial similarities XYZ is not water. ${ }^{16}$

\footnotetext{
${ }^{15}$ Notice that the well-worn example of jade is not a plausible example of the phenomenon we are concerned with here. Nephrite and jadeite are readily distinguishable by simple observational tests, including having different characteristic color, hardness and so on. The microstructure of jadeite explains jadeite's stereotypical properties, and the microstructure of nephrite explains nephrite's stereotypical properties, and both the explanans and explananda are distinct between the two cases, despite the fact that both of the explanans plausibly include 'is a greenish hard stone-like substance' or something like that.

${ }^{16}$ The semantic lesson of the case is then brought home by considering the time before 1750 when neither Earthians nor Twin-Earthians could determine the microstructure of anything.
} 
Some philosophers remain skeptical and do not feel any strong intuition to conclude that XYZ is not water on the basis of the Twin Earth case. A common reaction goes as follows: Putnam is envisaging a situation in which XYZ, the liquid on Twin Earth, is indistinguishable from water. If we were to encounter a liquid completely indistinguishable from water, a liquid that played all the same functional roles as water and had the same observable superficial properties as water, just with different microstructure, why would we want to say that it was not water? ${ }^{17}$

Now, something to notice is that in Putnam's original scenario the presumption is that that water and Twin Earth "water" are indistinguishable at first sight. The supposition that water and the superficially similar liquid on Twin Earth share the totality of functional roles in all contexts and all experiments, all the observed and all the observable properties is notoriously absent from Putnam's fiction. ${ }^{18}$

But let us put this seemingly exegetical point aside. To develop the skeptics' concern, let us consider a super-Twin Earth case, one in which by fiat we introduce the supposition that the totality of functional roles and all the observable (already observed or yet to be observed) properties of $\mathrm{H}_{2} \mathrm{O}$ and $\mathrm{XYZ}$ are the same. Considering such a scenario, we acknowledge, one may not have any clear inclination one way or another. It is not clear whether one should conclude that we have described a case in which there is one substance, water, with two different microstructures; or rather, two different substances with all the functions and superficial properties in common. In such a scenario, we grant, it really does not seem to make much of a difference which way one decides to go.

There are, however, at least two serious problems with the envisaged super-Twin Earth case. The first problem is that it is an impossible scenario, involving a contradiction in its basic posits. If the Twin-Earthians have discovered that what they call water has structure $\mathrm{XYZ}$, which by Putnam's stipulation is both complex and (obviously) distinct from $\mathrm{H}_{2} \mathrm{O}$, they

Back then, Putnam maintains, Earthians and Twin-Earthians meant different things when referring to their respective liquids, even if, at that time their psychological states, including everything they believed about the world that surrounded them, was the same. We discuss the semantic point below.

${ }^{17}$ The reaction as presented here arises from a combination of comments made on separate occasions by John Dupré and Catherine Elgin. We thank them both for pressing us on this issue.

${ }^{18}$ And in the pre-1750 scenario to which Putnam turns a couple of pages later, the supposition is that the totality of observed properties of the two liquids, up until that moment, are the same. The pre-1750 scenario is compatible with the future Earthians and Twin-Earthians observing that the microstructure of the liquids in question are respectively, and to simplify, $\mathrm{H}_{2} \mathrm{O}$ and $\mathrm{XYZ}$. 
did so with some experiments. Those experimental tests, then, give us observable contexts in which water and XYZ behave differently; without this supposition we cannot tell the story that Earthians travel to Twin Earth and find out that their lakes and rivers are full of XYZ rather than $\mathrm{H}_{2} \mathrm{O}$.

Second, the super-Twin Earth scenario stipulates that the totality of functional roles and the totality of superficial properties of $\mathrm{XYZ}$ and $\mathrm{H}_{2} \mathrm{O}$ coincide. But real science does not work by fiat. At any point in the history of science we cannot establish by stipulation, as we do in the fictional super Twin Earth story, that the totality of functional roles of substances with different microstructures is the same. And we have no guarantee that all the observable properties of substances that have, so far, been observed to have the same properties, are the same. The super-Twin Earth story pushes our intuitions towards the indecisiveness between two options (one substance with two different microstructures vs. two substances with all their functional roles in common), simply because it gives us, by stipulation, a certainty that we never have in real scientific investigation: the certainty that every single function, every possible application and observable property of two "stuffs" coincide; that no new differences in superficial behavior can be observed in future stages. But in the history of science way too many differences in behavior of seemingly identical kinds of stuff have been observed at later stages and explained as due to differences in molecular composition, atomic number or any of the other underlying characteristics that, according to the K\&P approach, may constitute the essences of substances.

For the discoverers and first users, platinum and palladium were for a long time difficult to tell apart; it was soon known that they were both rather unreactive, dense, highly resistant to corrosion and that they melted at extremely high temperatures. Subsequently both have been used in jewelry, dentistry and in catalytic converters. Nowadays the melting point of palladium has been observed to be the lowest among the transition metals, but it seems to us that even if the observed superficial properties, the functions and the behavior (to date) of the two metals were the same, once it was established that they belonged in different slots of the periodic table, no incautious oncologist would have proposed to administer a palladium compound to cancer patients, instead of cisplatin, carboplatin or oxaliplatin, the already tested an approved anti-cancer agents. In fact, when those cancer agents had already been approved by the FDA, and were widely prescribed, the effectiveness of palladium compounds was still a hypothesis, surely a hypothesis based on the many similarities between the two metals, but a hypothesis after all, one that has subsequently been tested. In a review article for the Royal Society of Chemistry, A.R. Kapdi and I.J.S. Fairlamb write: 
A significant amount of work has been carried out in understanding the applicability of platinum complexes and anti-cancer agents. However, dramatic side effects arising from the covalent interaction of platinum with DNA has prompted the development of other alternative metal-based anti-cancer drugs. Palladium complexes [. . .], particularly palladacycles or cyclopalladited have shown promising activity. The area is still nascent and requires further studies to be carried out. ${ }^{19}$

(Kapdi \& Fairlamb, 2014): 23.

The point is that even if two sorts of stuff having different microscopic constitution and/or structure have displayed all the same directly observable properties and behaviors so far, we will not expect or assume that this sameness of functional role will continue in all future contexts; so we will treat them as distinct substances.

To conclude, the super-Twin Earth scenario does not undercut Putnam's metaphysical morals. When initially described (“... all observable contexts, past present or future...”) it may cause our intuitions to waver; but then we notice that the scenario is actually selfcontradictory. And if we bring it back into the realm of what can be easily conceived, we see that the Putnamian intuition comes back full strength.

\section{The semantics: a comeback for cluster descriptivism?}

$\mathrm{H} \& \mathrm{~W}$ object also to the semantic anti-descriptivist stance endorsed by $\mathrm{K} \& \mathrm{P}$ and propose in its stead a form of cluster descriptivism, albeit a sophisticated version of the theory. The only argument they offer for returning to a form of descriptivism is the alleged failure of the K\&P thesis; if we have successfully rebutted their challenges to that thesis above, then there would seem to be little point in reconsidering descriptivism. Nevertheless, we feel that it is worthwhile to see that even a sophisticated variant of descriptivism is bound to be vulnerable to the same sorts of arguments offered by Kripke and Putnam over 40 years ago.

$\mathrm{H} \& \mathrm{~W}$ do not give a detailed account of what sophisticated descriptivism consists in, but they indicate that the theory would depart from classical cluster-descriptivism in two crucial respects: (i) the theory would not commit to the idea that all descriptions in the cluster are given equal weight; (ii) the theory would not commit to 'superficialism', i.e., the constraint that legitimate descriptions should involve only observable properties. ${ }^{20}$

\footnotetext{
${ }^{19}$ Subsequent results are reported in a more recent review article by (Fanelli et al., 2016).

${ }^{20}$ It should be noted that (i) is not a new tenet specific to sophisticated cluster descriptivism, as most discussions of cluster descriptivism in the literature take the view to involve appeal to
} 
This would allow us "to say that people have had many mistaken beliefs about gold . . . even if the number of mistaken beliefs were to outnumber the correct ones" (Häggqvist and Wikforss, 2017: 18) and thereby avoid Kripke's error arguments against descriptivism. On the other hand, a characteristic feature of cluster theories is the recognition that the complete cluster need not be fully in any one's speaker's mind, but overall it must be possessed by the linguistic community as a whole; this would evade the impact of Kripke's ignorance arguments.

But it is not clear at all that sophisticated cluster descriptivism is immune to the error objection. In the early stages of the use of a term there is no guarantee that the cluster will contain a core of correct beliefs about the extension. Arguably, the cluster of beliefs that researchers initially held about "dephlogisticated air" (which we now know as 'oxygen') held more falsehoods than truths, especially concerning the properties that those researchers themselves would have considered "core" or important; and the beliefs that were true may well have been insufficient to distinguish it from other gases. On the other hand the view appears to fall prey to the ignorance argument also. Again, in the early stages of the use of a term it seems quite possible that the cluster, even with a weighted core of more important members, will fail to have the right extension. For example, when samples of platinum were first named by Europeans, any plausible cluster associated with the term would have applied also to at least palladium, and perhaps other metals as well. But the people who introduced and started to use the term were holding samples of platinum (with some impurities) in their hands and intending to refer to that substance and only that substance, and we think they succeeded.

$\mathrm{H} \& \mathrm{~W}$ do not indicate if they are aware of those potential problems. But other descriptivists do. For instance (Sabbarton-Leary, 2010) defends a form of descriptivism according to which the meanings of natural kind terms are given by essentialist single descriptions, so that the meaning of 'tungsten' is given by the description 'the element with atomic number 74 '. Sabbarton-Leary notes:

One obvious objection to the view defended here is that there are some clear counterexamples. Terms like 'water' or 'gold', for instance, had significant prescientific currency. Hence, it seems plainly false to suppose that they could have been introduced in the systematic function outlined above. (Sabbarton-Leary, 2010): 428 
Sabbarton-Leary proposes to solve this difficulty following a strategy suggested by Joseph LaPorte (LaPorte, 2004). According to LaPorte pre-scientific terms are open-textured, and their meanings are refined in time as science progresses. Sabbarton-Leary proposes that prescientific uses of words like 'water' were vague and quite likely guided by interests very different from those of chemistry and other sciences. It is science that eventually fixes the (scientific) meaning of those terms.

We do not think that the appeal to LaPorte's considerations is of any help to the descriptivist, whether defending single- or cluster-descriptivism. ${ }^{21}$ For the issue of ignorance and error does not arise only for vernacular, pre-scientific uses of terms. Scientists themselves in the early stages of identification of a substance, using a term scientifically, may attach to the term descriptions or clusters of descriptions that are massively wrong and insufficient to determine a unique referent. The case already mentioned of "dephlogisticated air" may be a good example of this. While 'dephlogisticated air' is a description, Lavoisier, who considered it to be an elementary substance, dubbed it 'oxygen' and ascribed a number of theoretical properties to it, many of which we now regard as mistaken. But he was nevertheless referring to, and scientifically studying, oxygen.

Certainly, H\&W do not endorse Sabbarton-Leary's brand of essentialist descriptivism. But they have the same problems: ignorance and error, at least in the early stages of scientific knowledge about a substance.

Of course, once science has revealed enough important facts about a natural kind such as water or platinum, ignorance and error are by and large dispelled, and clusters that get the extension intuitively right become available to the community; and, as (Needham, 2011) argues, they may not even need to mention microstructural properties. But if they don't include the properties that the K\&P view would consider essential, they remain vulnerable to Twin Earth type counterfactual thought experiments. And conversely, if the clusters do contain in their core the microstructural properties that the $\mathrm{K} \& \mathrm{P}$ view considers essential, as in Sabbarton-Leary's approach, then Twin Earth cases cannot be produced. But then the success of the theory is arguably parasitic on the correctness of the KP thesis that H\&W set out to criticise.

\section{Conclusion}

${ }^{21}$ Although we reject the application of LaPorte's considerations in the defense of descriptivism, this is not to deny the plausibility of some of LaPorte's conclusions. 
We have argued that the line of argument pursued by H\&W and others should not lead us to reject the metaphysical conclusions of the K\&P approach nor to abandon the concomitant semantic lessons. This does not amount to an all-out endorsement of the picture. In fact, there are important issues to be explored and doubts to be raised about the applicability of the view to all kinds of kinds and kind terms (such as biological taxonomic kinds and unstable elements or compounds); and the issues that (LaPorte, 2004) discusses suggest that the view may need to be revised in order to account for some vernacular, prescientific uses of terms and their connection to subsequent scientific usage. Certainly, as we have noted, the K\&P approach should not be seen as striving to impose a hegemonic metaphysical and semantic stance. But what is clearly the case, we believe, is that the antimicroessentialist line of argument that has become common in the philosophy of science literature, pursued by $\mathrm{H} \& \mathrm{~W}$ and others, does not provide any reason to reject the K\&P view when it comes to the central substance natural kind terms they discuss such as 'water' and 'gold'.

\section{References:}

Beebee, H., \& Sabbarton-Leary, N. (2010). On the abuse of the necessary a posteriori. In H. Beebee \& N. Sabbarton-Leary (Eds.), The Semantics and Metaphysics of Natural Kinds. Routledge.

Chang, H. (2012). Is Water H2O? Evidence, Realism and Pluralism. Springer Netherlands.

Fanelli, M., Formica, M., Fusi, V., Giorgi, L., Micheloni, M., \& Paoli, P. (2016). New trends in platinum and palladium complexes as antineoplastic agents. Coordination Chemistry Reviews, 310, 41-79. https://doi.org/10.1016/j.ccr.2015.11.004

Häggqvist, S., \& Wikforss, Å. (2017). Natural Kinds and Natural Kind Terms: Myth and Reality. The British Journal for the Philosophy of Science, 1-23. Retrieved from http://dx.doi.org/10.1093/bjps/axw041

Hendry, R. F. (2006). Elements, compounds and other chemical kinds. Philosophy of Science, $73(5)$.

Kapdi, A. R., \& Fairlamb, I. J. S. (2014). Anti-cancer palladium complexes: a focus on PdX 2 L 2, palladacycles and related complexes. Chemical Society Reviews, 43(13), 4751- 
4777.

LaPorte, J. (2004). Natural Kinds and Conceptual Change. Cambridge University Press.

Leslie, S.-J. (2013). Essence and natural kinds: When science meets preschooler intuition. Oxford Studies in Epistemology, 4.

Needham, P. (2002). The discovery that water is H2O. International Studies in the Philosophy of Science, 16(3).

Needham, P. (2011). Microessentialism: What is the Argument? Noûs, 45(1).

Nimtz, C. (2017). Paradigm Terms: The Necessity of Kind Term Identifications Generalized. Australasian Journal of Philosophy, 95(1).

Putnam, H. (1975). The meaning of 'meaning'. In K. Gunderson (Ed.), Language, Mind and Knowledge. Minnesota Studies in the Philosophy of Science, 7. University of Minnesota Press.

Putnam, H. (1990). Is Water Necessarily H2O? In J. Conant (Ed.), Realism with a Human Face. Harvard University Press.

Sabbarton-Leary, N. (2010). Descriptivist Reference from Metaphysical Essence. Dialectica, 64(3).

Zvolenszky, Z. (2012). Searle on Analyticity, Necessity, and Proper Names. Organon F: Medzinárodný Časopis Pre Analytickú Filozofiu, 19(2). 